\title{
Analysis of bacterial communities of infected primary teeth in a Mexican population
}

\author{
Enid Karina Salas-López ${ }^{1}$, Sergio Casas-Flores ${ }^{2}$, Nguyen Esmeralda López-Lozano ${ }^{3}$, Esther Layseca- \\ Espinosa $^{4}$, Christian A. García-Sepúlveda ${ }^{4}$, Perla del Carmen Niño-Moreno ${ }^{5}$, Amaury Pozos-Guillén ${ }^{1}$
}

${ }^{1} \mathrm{PhD}$, Facultad de Estomatología, Universidad Autónoma de San Luis Potosí, San Luis Potosí, México

${ }^{2} \mathrm{PhD}$, IPICYT, División de Biología Molecular, San Luis Potosí, México

${ }^{3}$ PhD, IPICYT, División de Ciencias Ambientales, San Luis Potosí, México

${ }^{4} \mathrm{PhD}$, Facultad de Medicina, Universidad Autónoma de San Luis Potosí, San Luis Potosí, México

${ }^{5}$ PhD, Facultad de Ciencias Químicas, Universidad Autónoma de San Luis Potosí, San Luis Potosí, México

Correspondence:

Facultad de Estomatología

Universidad Autónoma de San Luis Potosí

Av. Dr. Manuel Nava \#2, Zona Universitaria

C.P. 78290, San Luis Potosi, S.L.P. México

apozos@uaslp.mx

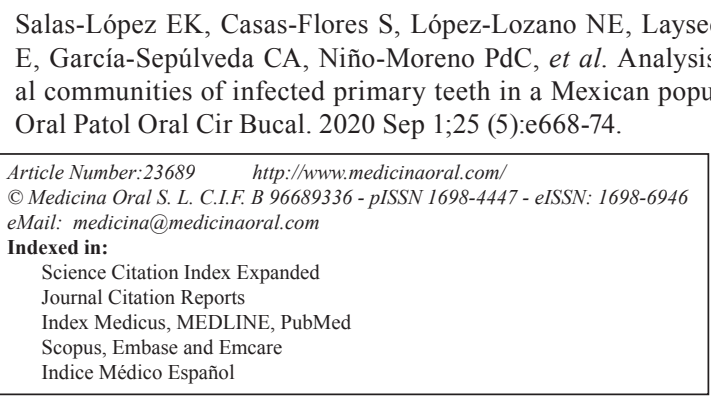

\begin{abstract}
Background: The objective of this study was to describe the bacterial communities associated with pediatric patients with endodontic infections of temporal teeth by targeting the $16 \mathrm{~S}$ rRNA gene using pyrosequencing. Material and Methods: Microbiological samples were obtained from the lower primary molars of thirteen 13 pediatric patients with dental infections. An aspiration method for microbiological sampling was used. The identification of microbiota employing the pyrosequencing method by targeting the $16 \mathrm{~S}$ gene was performed.

Results: Ribosomal 16S RNA gene sequences were amplified, obtaining a total of 16,182 sequences from 13 primary infected molars (13 different individuals) by pyrosequencing. Bacteroidetes phyla $(35.15 \%)$ were the most abundant followed by Firmicutes (33.3\%) and Fusobacteria (10.05\%); the presence of specific pathogenic bacteria was determined as well.

Conclusions: The infected root canal of primary teeth contains a high diversity of anaerobic bacteria, and Bacteroidetes, Firmicutes, and Fusobacteria phyla were the most abundant; Prevotella and Streptococcus genera were the most prevalent.
\end{abstract}

Key words: Pyrosequencing, deciduous teeth, oral bacterial microbiota, $16 \mathrm{~S}$ rRNA, taxonomy. 


\section{Introduction}

The invasion of microorganisms into the root canal system via dentinal tubules, mainly exposed by dental caries, represent a crucial role in endodontic/periapical infections; this situation is a common clinical problem in primary teeth. In severe cases, it may cause pain, swelling, abscesses, and even the premature loss of teeth. Microorganisms of the oral cavity have been described as oral microbiota, oral microflora, and recently, as the oral microbiome, which includes a community integrated by commensals, symbiotic, and pathogenic microorganisms, whose interactions can be related to the development of oral diseases such as caries and endodontic/periapical infections (1-3).

The relationship of microorganisms with endodontic pathologies has been recognized for more than 50 years, when pathologic changes were observed resulting from untreated experimental pulp exposures in germ-free rats as compared with conventional rats with a normally complex microflora (4). Until 1970, the most common bacterial group isolated by culture from the root canals of permanent teeth was Viridans streptococcus. Then, with the advance of strictly anaerobic culture techniques, the concept of endodontic infection changed due to that anaerobic microorganisms, which had been rarely isolated, were observed as the predominant endodontic microbiota in permanent teeth with necrotic pulp and periapical lesions (5). In general, a microbial variety and a spectrum of microbial communities related to endodontic infections have been described as primary, secondary, and persistent infections (6). Root canals could show different types of infections, and they are associated with different clinical conditions, which cause acute or chronic periradicular lesions. The composition of microbiota varies depending on the infection and the type of periradicular lesion. Overall, the infections are mixed, with the predominance of anaerobic and facultative bacteria $(6,7)$.

In both primary and permanent teeth, several bacterial species, predominantly Gram-negative anaerobic microorganisms, have been similarly associated in the etiology of endodontic infections (8). However, the microbial profiles of permanent-tooth root canals have been evaluated to a greater extent, and these reports have shown a large variety of species, for example, Lactobacillus, Veionella, Prevotella, Fusobacterium, Streptococcus, Tanerella, Bacteroidetes, Actinobacteria, and others (6). Recently, through the development of anaerobic cultures and next-generation sequencing tools, it has been possible to identify aerobic and anaerobic microorganisms associated with infections in permanent teeth. However, few studies (9-13) have been addressed to identify the great diversity of microorganisms from primary teeth.

Pulp necrosis is commonly originated by caries, trauma, or other causes; in primary teeth, this condition might lead to periapical disease and could affect the permanent tooth germ. Pulp therapy in primary teeth with necrotic pulps aims at eliminating the infection and preventing early tooth loss (10). Bacteria play an important role on the establishment of pulp infection, and the main purpose of clinical treatment is the elimination of pulp infections from the root canal. It is indispensable to identify the pathogens isolated from infected primary teeth so that the appropriate antimicrobial agents can be utilized locally to eradicate these microorganisms. The objective of this study was to describe the bacterial communities associated with pediatric patients with endodontic infections of temporal teeth by targeting the $16 S$ rRNA gene using pyrosequencing.

\section{Material and Methods}

- Patients

Patients were recruited from the Clinic for Pediatric Dentistry, Faculty of Dentistry, San Luis Potosi University, Mexico. The objective of the study was explained to either the parents or legal guardians, and written informed consent was obtained. This study included 13 patients (seven males and six females) between 4 and 7 years of age, who presented at the clinic for dental consultation and intervention. Inclusion criteria were children in good general health and with mandibular molars with carious lesion with or without direct exposure to the oral environment, containing at least one necrotic canal, abscess, or sinus tract. In addition, periapical xrays of the selected teeth using the standard paralleling technique were taken to verify the presence of radiolucent area(s) in the furcation or periapical region and with at least two-thirds of the root remaining. Patients who had received antibiotics up to 4 weeks prior to sampling, who had used antimicrobial mouthwashes, and who presented with any systemic disease were excluded from the study. Demographic and clinical characteristics are shown in Table 1.

- Isolation, operative field disinfection, and microbiological sampling

After antisepsis of the oral cavity, local anesthesia was induced employing an infiltration. Each treated molar was cleaned and isolated with a rubber dam. Provisit (Casa Idea, SA de CV, México) was placed along the molar-rubber dam interface to prevent the leakage of saliva into the operative field. To disinfect the operative field, the following procedure was carried out in each tooth: the tooth crown, surrounding rubber dam, and clamp were swabbed with 30\% $\mathrm{H} 2 \mathrm{O} 2$ followed by $5.25 \% \mathrm{NaOCl}$ for $1 \mathrm{~min}$ each. Caries was removed with a bur cooled with sterile saline solution; a sterile cotton pellet was placed on the floor of the chamber to prevent the penetration of disinfectants into the canals, and, with another sterile bur, the root canal was accessed. 
Table 1: Demographic and clinical characteristics of the patients.

\begin{tabular}{|c|c|c|c|c|c|}
\hline Patient & Age & Sex & Pain & Periapical abscess & Previous restauration or cavity \\
\hline 1 & 6 & $\mathrm{~F}$ & $\mathrm{Y}$ & $\mathrm{Y}$ & $\mathrm{Y}$ \\
\hline 2 & 6 & $\mathrm{~F}$ & $\mathrm{~N}$ & $\mathrm{~N}$ & $\mathrm{~N}$ \\
\hline 3 & 5 & $\mathrm{~F}$ & $\mathrm{Y}$ & $\mathrm{Y}$ & $\mathrm{N}$ \\
\hline 4 & 7 & $\mathrm{~F}$ & $\mathrm{~N}$ & $\mathrm{Y}$ & $\mathrm{Y}$ \\
\hline 5 & 7 & $\mathrm{M}$ & $\mathrm{Y}$ & $\mathrm{Y}$ & $\mathrm{Y}$ \\
\hline 6 & 4 & $\mathrm{M}$ & $\mathrm{N}$ & $\mathrm{N}$ & $\mathrm{Y}$ \\
\hline 7 & 4 & $\mathrm{M}$ & $\mathrm{N}$ & $\mathrm{N}$ & $\mathrm{N}$ \\
\hline 8 & 7 & $\mathrm{M}$ & $\mathrm{Y}$ & $\mathrm{Y}$ & $\mathrm{Y}$ \\
\hline 9 & 7 & $\mathrm{M}$ & $\mathrm{Y}$ & $\mathrm{N}$ & $\mathrm{Y}$ \\
\hline 10 & 5 & $\mathrm{M}$ & $\mathrm{Y}$ & $\mathrm{N}$ & $\mathrm{N}$ \\
\hline 11 & 7 & $\mathrm{M}$ & $\mathrm{Y}$ & $\mathrm{Y}$ & $\mathrm{N}$ \\
\hline 12 & 4 & $\mathrm{~F}$ & $\mathrm{Y}$ & $\mathrm{N}$ & $\mathrm{Y}$ \\
\hline 13 & 4 & $\mathrm{~F}$ & $\mathrm{Y}$ & & $\mathrm{Y}$ \\
\hline
\end{tabular}

$\mathrm{F}=$ Female, $\mathrm{M}=$ Male, $\mathrm{Y}=$ Presence, $\mathrm{N}=$ Absence

The cavity and field were again disinfected as described previously. The $\mathrm{NaOCl}$ was inactivated with $10 \%$ sodium thiosulfate for $1 \mathrm{~min}$. Disinfection control samples were taken with sterile cotton pellets from the coronal surface of the tooth, rubber dam, and clamp, and immediately inoculated onto blood agar plates (BBL Becton Dickinson, México). The samples were then transferred to an aerobic incubator at $37^{\circ} \mathrm{C}$ for $24-48 \mathrm{~h}(8)$. For sample collection, an endodontic file was passively introduced up to $1 \mathrm{~mm}$ from the radiographic apex or from the limit of root resorption and was gently moved in an apex-crown direction against the intracanal wallsAfter this, the file was removed and, using the washing and aspiration protocol with a plastic tip inserted into an electronic micropipette, the contents of the root canal was placed into a $1.5-\mathrm{mL}$ polyethylene tube containing $1.0 \mathrm{~mL}$ of phosphate buffered saline (PBS) solution and snap-frozen at $-80 \mathrm{oC}$ until analysis (14).

- Total DNA extraction of samples

Each sample was treated as described by Casas-Flores et al. (15); briefly, $200 \mu \mathrm{g}$ of glass beads were added to each sample, and then $15 \mu \mathrm{L}$ of lysozyme $20 \mathrm{mg} / \mathrm{mL}$ was added and mixed. Samples were incubated during $2 \mathrm{~h}$ at $37^{\circ} \mathrm{C}$, and $5 \mu \mathrm{L}$ of proteinase $\mathrm{K}$ and $50 \mu \mathrm{L}$ of $20 \%$ SDS were added. Samples were incubated during $2 \mathrm{~h}$ at $65^{\circ} \mathrm{C}$ and mixed at each 30-min interval. Thereafter, 1 volume of chloroform was added, centrifuged at 13,000 rpm for $10 \mathrm{~min}$, and the aqueous phases were recovered, 1 volume of $70 \%$ isopropanol was added, and the mix was incubated overnight at $-20^{\circ} \mathrm{C}$. Then, the samples were centrifuged during $20 \mathrm{~min}$ at 13,000 rpm, the supernatant was poured, and the pellet was washed with $750 \mu \mathrm{L} 70 \%$ ethanol, centrifuged during $5 \mathrm{~min}$ at 13,000 rpm, and ethanol was eliminated by evaporation. The pellet was suspended in $20 \mu \mathrm{L}$ of sterile Milli-Q H2O.

- PCR amplification and pyrosequencing

Each PCR reaction targeting the $16 S$ rRNA gene was performed using $0.3 \mu \mathrm{L}$ each of $16 \mathrm{~S}$ rRNA universal primers 533F (16) and 1391R (17) at an initial concentration of $10 \mu \mathrm{M}$ (Table 2).

Table 2: Total number of samples and total sequences processed.

\begin{tabular}{|c|c|c|c|}
\hline Sample & Total & With hit (\%) & Without hit (\%) \\
\hline 1 & 1,217 & $1,164(95.6 \%)$ & $53(4.4 \%)$ \\
\hline 2 & 1,543 & $1,498(97.1 \%)$ & $45(2.9 \%)$ \\
\hline 3 & 2,709 & $2,701(99.7 \%)$ & $8(0.3 \%)$ \\
\hline 4 & 1,271 & $1,239(97.5 \%)$ & $32(2.5 \%)$ \\
\hline 5 & 2,491 & $2,485(99.8 \%)$ & $6(0.2 \%)$ \\
\hline 6 & 1,685 & $1,682(99.8 \%)$ & $3(0.2 \%)$ \\
\hline 7 & 2,409 & $2,404(99.8 \%)$ & $5(0.2 \%)$ \\
\hline 8 & 1,258 & $298(23.7 \%)$ & $960(76.3 \%)$ \\
\hline 9 & 2,397 & $2,047(85.4 \%)$ & $350(14.6 \%)$ \\
\hline 10 & 2,867 & $2,805(97.8 \%)$ & $62(2.2 \%)$ \\
\hline 11 & 2,445 & $2,705(84.9 \%)$ & $370(15.1 \%)$ \\
\hline 12 & 1,550 & $817(52.7 \%)$ & $733(47.3 \%)$ \\
\hline 13 & 3,624 & $3,178(87.7 \%)$ & $446(12.3 \%)$ \\
\hline
\end{tabular}


Furthermore, $2.5 \mu \mathrm{L}$ of $25 \mathrm{mM} \mathrm{MgCl} 2,0.125 \mathrm{U}$ of Go Taq (Promega), 14.4 $\mu \mathrm{L}$ of sterile double-distilled water, and 0.4 of $10 \mathrm{mM}$ dNTP were added. The reaction was performed in a GeneAmp system (Applied Biosystems) as follows: an initial denaturizing step at $94^{\circ} \mathrm{C}$ during 2 min, followed by 30 cycles at $94^{\circ} \mathrm{Cduring} 1 \mathrm{~min}, 60^{\circ} \mathrm{C}$ during $1 \mathrm{~min}$, and $72^{\circ} \mathrm{C}$ during 1:30 min, and completed with a final extension step at $72^{\circ} \mathrm{C}$ during $7 \mathrm{~min}$. Ten $\mu \mathrm{L}$ of each PCR product was resolved in a $1 \%$ agarose gel stained with ethidium bromide. A re-amplification of the PCR products was performed using the barcode primers of 454 Roche as recommended by the supplier. The reamplified PCR products were purified by means of a MinElute PCR purification kit (Qiagen, Valencia, CA, USA), pooled, and sequenced in a 454 Life Sciences GS FLX system at the Laboratorio Nacional de Genómica para la Biodiversidad, CINVESTAV-Irapuato, Mexico, using the GS FLX Titanium Sequencing Kit XL, which allows for the sequencing of amplicons of $800 \mathrm{bp}$ (base pairs).

- Data analysis

Mothur open source software (v.1.36.1) was utilized for the analysis of $16 S$ rRNA gene libraries. Sequences with homopolymer runs of eight or more bases, those with more than two mismatches with the sequencing primer, and a Q-value average below 25 were discarded. The potential occurrence of chimeric sequences was analyzed using the UCHIME algorithm. Sequences were aligned against the SILVA 123 16S/18S rRNA gene database, utilizing the Nearest alignment space termination (NAST) algorithm and trimmed for the optimal alignment region. With the non-redundant sequences, a pairwise distance matrix was calculated and reads were clustered into Operational taxonomic units (OTU) at a 3\% distance using the furthest neighbor method. Mothur's Bayesian classifier and the SILVA 123 refer- ence set were employed to categorize taxonomically the sequences and the OTU. Statistical analysis, heat maps, and graphics were performed using the R statistical program (http://www.r-project.org/).

\section{Results}

A total of 16,182 sequences from 13 primary infected teeth were obtained by 454 pyrosequencing. These sequences were submitted to a quality control analysis to remove low-quality sequences and possible chimeras, obtaining 15,102 sequences, representing $93 \%$ of the total of sequences obtained with an average length of $800 \mathrm{bp}$. The number of reads by sample ranged from 583-2,240. Sequences that passed quality control were assigned to 889 OTU (Operational taxonomic units) by using a cutoff of $97 \%$ sequence identity (Table 2) (Fig. 1). The sample with the lowest number of OTU was from 54 (patient 1), whereas the highest number of OTU was from 116 for sample 13. In agreement with these results, the sample containing the highest number of reads demonstrated the highest number of OTU; however, that was not the rule, in that some samples with relative higher numbers of reads revealed low numbers of OTU (sample 3) and vice versa (sample 4). From the OTU, eight bacterial phyla were obtained with a relative abundance greater than $1 \%$, and 23 bacterial genera with a relative abundance greater than 5\% were assigned.

Eight phyla were found in the 13 teeth (Fig. 2). Regarding relative abundance, the Bacteroidetes phyla (35.15\%) was the most abundant, followed by Firmicutes (33.3\%) and Fusobacteria (10.05\%) and, found at lesser amounts were Actinobateria (13.5\%), Spirochetes (2.6\%), and Synergist (5.3\%). A total of 2,035 genera were found; the most abundant genera at a relatively high abundance were Prevotella and Streptococcus (Fig. 3).

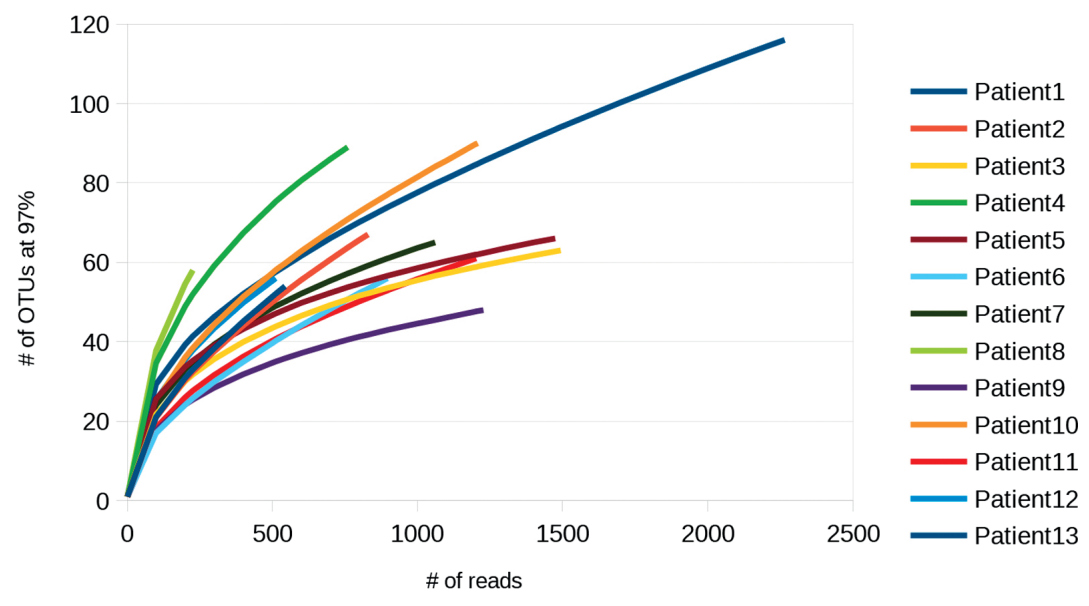

Fig. 1: Rarefaction curves of bacterial OTU found in the infected primary teeth of Mexican patients. The readings were grouped into Operational taxonomic units (OTU) with a divergence of $3 \%$. 


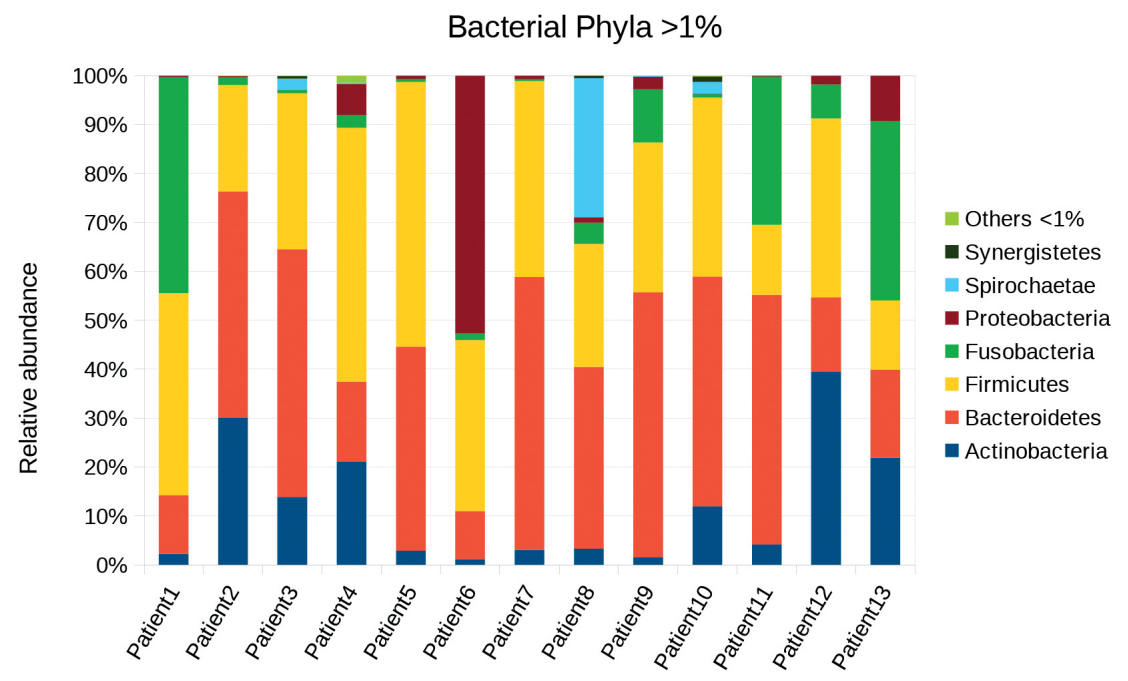

Fig. 2: Bacterial phyla found in the infected primary teeth of 13 Mexican patients. The sample percentage of the relative abundance of each phylum of $>1 \%$ in the libraries are shown.

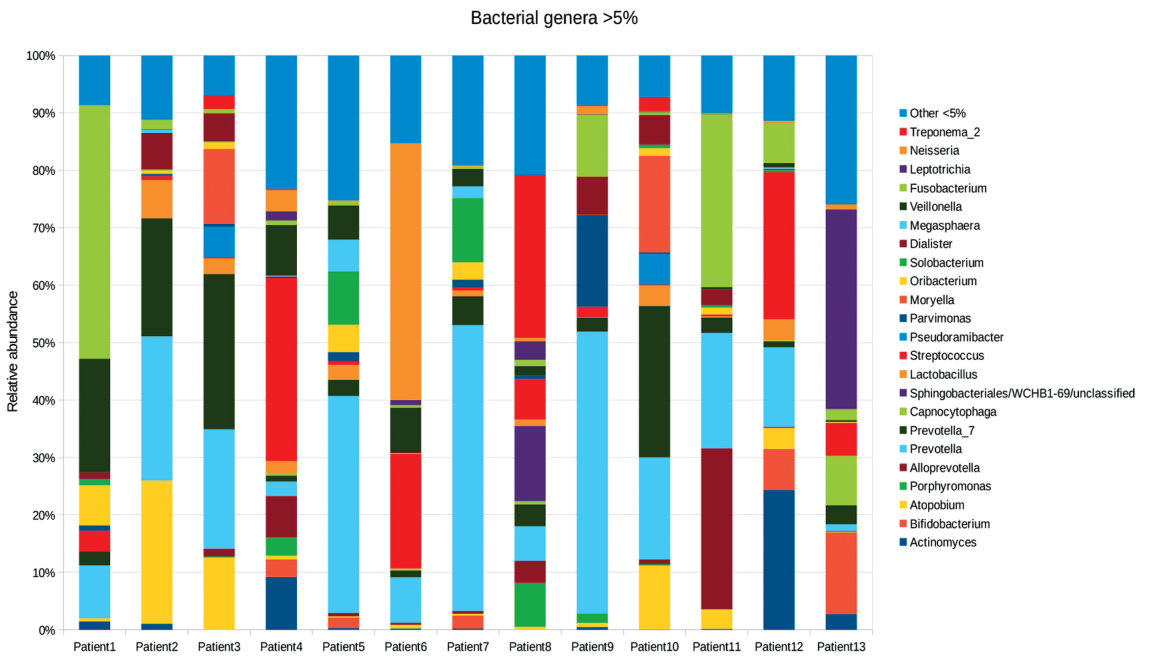

Fig. 3: Bacterial genera found in the infected primary teeth of 13 Mexican patients. The percentages of the relative abundance of each genus of $>5 \%$ are shown.

\section{Discussion}

The oral cavity has one of the highest amounts of microorganisms, mainly bacteria, distributed among more than 700 species. Bacteria are the main etiologic agents of primary endodontic infections. In these infections, multiple species have frequently been detected, predominantly anaerobic bacteria. Over 500 different bacterial species have been identified in infected root canals by different methods, such as culture, conventional
PCR molecular tools, and new-generation sequencing, including pyrosequencing $(18,19)$. There are numerous methods for evaluating the root canal microbiome; however, they possess low or limited coverage. Pyrosequencing is a deep-coverage sequencing technique; the 454 pyrosequencing technology facilitates metagenomic study through a high-throughput, deep-coverage, massively parallel, and multiplex barcoded approach (20). Anaerobic bacteria are those most commonly isolated 
from endodontic infections, mainly Gram-positive anaerobic cocci, such as Peptostreptococcus anaerobius, Peptostreptococcus micros, and Gram-negative anaerobic rods, including Porphyromonas endodontalis, Porphyromonas gingivalis, Prevotella intermedial Prevotella nigrescens, Prevotella melaninogenica, Fusobacterium nucleatum, and Fusobacterium necrophorum (21).

In this study, up to $88.8 \%$ of the total of different bacteria identified in the different samples exhibited a higher amount of species compared with those recently obtained by pyrosequencing. For instance, Li et al. (22) found 43 species in a total of nine teeth, whereas Ribeiro et al. (23) described 70 species. Another study with nine teeth reported five phyla and contained 17 genera and 105 species (24). Santos et al. (25) used $16 S$ rRNA, to identify endodontic bacteria and detected Firmicutes as the most abundant phylum, followed by Bacteroidetes. In the present study, Bacteroidetes was the most abundant phylum with $29.6 \%$, followed by Firmicutes with $23.2 \%$, and Fusobacteria with $13.1 \%$.

To our knowledge, there are few studies describing the microbiota in primary teeth $(5,8-13)$. In this regard, it was reported that 10 bacterial species are commonly found in temporal teeth, Fusobacterium nucleotum and Prevotella intermedia the most abundant species in endodontic infections (13). In other recent study, Yun et al. (11) analyzed 10 infected deciduous teeth by means of pyrosequencing, yielding a total of 64,291 $16 \mathrm{~S}$ rRNA gene sequences; the most abundant phylum was Proteobacteria (50.4\%), followed by Firmicutes and Bacteroidetes with 25.8 and 9.5\%, respectively, and 187 genera, determining that Neisseria, Streptococcus, and Veionella were the most abundant genera. Regarding genera, the results of these authors are in agreement with those of the present study, because the authors found Streptococcus and Veionella at a higher amount. However, the authors found lower percentages of the Prevotella genus, which is in disagreement with the present results. Fusobacterium is associated with severe endodontic infection and with polymicrobial infection (26). Also, is recognized the ability of Fusobacterium to intensify the pyogenic capacity of Streptococcus constellatus strains and to suppress their phagocytic killing by human polymorphonuclear leukocytes (27). On the other hand, bacterial combinations of Porphyromonas, Parvimonas micra, and Fusobacterium are related with pain intensity (28).

In studies of this nature, bacterial recovery is essential, for which different methods have been used, and the bacterial recovery capacity may depend on the sampling method. In order to reduce the weaknesses of sampling by using paper points, this study used a novel method involving the washing/aspirating of the root-canal (14). This method reduces the exposure of the microorgan- isms to the external environment. It is suggested that with this technique, the microbial load is greater and allows a greater recovery of microorganisms (number and variety). In addition, using a negative control on all of the samples ensures that the microorganisms found were exclusively from the root canal and not transferred by the rubber dam.

More studies with temporal teeth are needed in order to have a comparative parameter, because the microorganisms reported are strictly aerobic, and more and more microorganisms resistant to antibiotics are being identified every day; uncontrolled use of antibiotics, and self-medication of antibiotics aggravates this clinical problem (29). In this respect, the pharmacological treatment for these patients must be considered, as well as the cleaning of the conduct of the tooth at the moment of the pulp therapy.

Also, more studies are needed to evaluate variables such as the ethnic origin, feeding habits, hygiene, oral health, type of infection, sociodemographic context, among others. It is important to know the inhabiting microorganisms of infected temporal teeth, which could be giving rise to and/or aggravating a persistent infection in a different part of the human body. Additionally, given the great variety of endodontic microorganisms and their diverse virulence factors, the exact microbial species can be determined in terms of whether any specific group of bacteria is associated with specific endodontic symptoms and clinical signs (30).

Finally, the results revealed the presence of combinations of bacterial species, with a majority of anaerobic bacteria, in the root canal of infected primary teeth. It is necessary to carry out specific studies that include hygiene habits, diet, sex, and different living conditions in order to establish an association among microorganisms. These observations suggest investigating their possible clinical implications and the designing of novel therapeutic strategies in the field of irrigating solutions and filling materials employed in endodontic treatments as disinfectants.

\section{Conclusions}

The infected root canal of primary teeth contains a high diversity of anaerobic bacteria, and Bacteroidetes, Firmicutes, and Fusobacteria phyla were the most abundant of these. The genera Prevotella and Streptococcus were the most prevalent.

\section{References}

1. Struzycka I. The oral microbiome in dental caries. Pol J Microbiol. 2014;63:127-35.

2. Liu B, Faller LL, Klitgord N, Mazumdar V, Ghodsi M, Sommer $\mathrm{DD}$, et al. Deep sequencing of the oral microbiome reveals signatures of periodontal disease. PLoS One. 2012;7:e37919.

3. Dewhirst FE, Chen T, Izard J, Paster BJ, Tanner ACR, Yu W, et al. The human oral microbiome. J Bateriol. 2010;192:5002-17.

4. Kakehashi S, Stanley H, Fitzgerald R. The effects of surgical ex- 
posures of dental pulps in germ-free and conventional laboratory rats. Oral Surg Oral Med Oral Pathol. 1965;20:340-9.

5. Da Silva L, Nelson-Filho P, Faria G. Bacterial profile in primary teeth with necrotic pulp and periapical lesions. Braz Dent J. 2006;17:144-8

6. Siqueira JF Jr, Rôças IN. Distinctive features of the microbiota associated with different forms of apical periodontitis. J Oral Microbiol. 2009;1:1-12.

7. Manzur A, Gonzalez A, Pozos A, Silva-Herzog D, Friedman S. Bacterial quantification in teeth with apical periodontitis related to instrumentation and different intracanal medications: A randomized clinical trial. J Endod. 2007;33:114-8.

8. Cogulu D, Uzel A, Oncag O, Eronat C. PCR-based identification of selected pathogens associated with endodontic infections in deciduous and permanent teeth. Oral Surg Oral Med Oral Pathol Oral Radiol Endod. 2008;106:443-9.

9. Ledezma-Rasillo G, Flores-Reyes H, Gonzalez-Amaro AM, Garrocho-Rangel A, Ruiz-Rodriguez MS, Pozos-Guillen AJ. Identification of cultivable microorganisms from primary teeth with necrotic pulps. J Clin Pediatr Dent. 2010;34:329-34.

10. Tavares WL, Neves de Brito LC, Teles RP, Massara MLA, Ribeiro Sobrinho AP, Haffajee AD, et al. Microbiota of deciduous endodontic infections analysed by MDA and Checkerboard DNA-DNA hybridization.. Int Endod J. 2011;44:225-35.

11. Yun KH, Lee HS, Nam OH, Moon CY, Lee JH, Choi SC. Analysis of bacterial community profiles of endodontically infected primary teeth using pyrosequencing. Int J Paediatr Dent. 2017;27:56-65.

12. Nelson-Filho P, Ruviére DB, de Queiroz AM, de Paula-Silva FWG, Silva RABD, Lucisano MP, et al. Comparative molecular analysis of Gram-negative bacteria in primary teeth with irreversible pulpitis or periapical pathology. Pediatr Dent. 2018;40:259-64.

13. Thimmegowda U, Thomas J, Bilichodmath S, Preethi N. Identification of specific anaerobic bacteria in endodontic infections of primary teeth-A PCR study. Int J Clin Pediatr Dent. 2019;12:1-4.

14. Bernal-Treviño A, González-Amaro AM, Méndez González V, Pozos-Guillen A. Frequency of Candida in root canals of teeth with primary and persistent endodontic infections. Rev Iberoam Micol. 2018;35:78-82.

15. Casas-Flores S, Gómez-Rodríguez EY, García-Meza JV. Community of thermoacidophilic and arsenic resistant microorganisms isolated from a deep profile of mine heaps. AMB Express. 2015;5:132. 16. Weisburg WG,Barns SM,PelletierDA,LaneDJ.16SribosomalDNA amplification for phylogenetic study. J Bacteriol. 1991;173:697-703. 17. Turner S, Pryer KM, Miao VPW, Palmer JD. Investigating deep phylogenetic relationships among cyanobacteria and plastids by small subunit rRNA sequence analysis. J Eukaryot Microbiol. 1999;46:327-38.

18. Siqueira Jr JF, Rôças IN. Diversity of endodontic microbiota revisited. J Dent Res. 2009;88:969-81

19. Aas JA, Paster BJ, Stokes LN, Olsen I, Dewhirst FE. Defining the normal bacterial flora of the oral cavity. J Clin Microbiol. 2005;43:5721-32.

20. Keskin C, Demiryürek EÖ, Onuk EE. Pyrosequencing analysis of cryogenically ground samples from primary and secondary/persistent endodontic infections. J Endod. 2017;43:1309-16.

21. Stefanopoulos PK, Kolokotronis AE. The clinical significance of anaerobic bacteria in acute orofacial odontogenic infections. Oral Surg Oral Med Oral Pathol Oral Radiol Endod. 2004;98:398-408.

22. Li L, Hsiao WW, Nandakumar R, Barbuto SM. Analyzing endodontic infections by deep coverage pyrosequencing. J Dent Res. 2010;89:980-4

23. Ribeiro AC, Matarazzo F, Faveri M. Exploring bacterial diversity of Endodontic microbiota by cloning and sequencing $16 \mathrm{~S}$ rRNA. J Endod. 2011;37:922-6.

24. Chalmers NI, Oh K, Hughes CV, Pradhan N, Kanasi E, Ehrlich Y, et al. Pulp and plaque microbiota of children with severe early childhood caries. J Oral Microbiol. 2015;7:25951.

25. Santos AL, Siqueira JF Jr, Rocas IN, Jesus EC. Comparing the bacterial diversity of acute and chronic dental root canal infections.
PloS One. 2011;6:e28088.

26. Peterson LJ. Contemporary management of deep infections of the neck. J Oral Maxillofac Surg. 1993;51:226-31.

27. Nagashima H, Takao A, Maeda N. Abscess forming ability of streptococcus milleri group: synergistic effect with Fusobacterium nucleatum. Microbiol Immunol. 1999;43:207-16.

28. Shweta, Prakash SK. Dental abscess: a microbiological review. Dent Res J. 2013;10:585-91.

29. González-López E, Vitales-Noyola M, González-Amaro AM, Méndez-González V, Hidalgo-Hurtado A, Rodríguez-Flores R, et $a l$. Aerobic and anaerobic microorganisms and sensitivity of odontogenic maxillofacial infections. Odontology. 2019;107:409-17.

30. Gomes BPFA, Herrera DR. Etiologic role of root canal infection in apical periodontitis and its relationship with clinical symptomatology. Braz Oral Res. 2018;32:e69.

\section{Funding}

None declared.

\section{Conflict of interest}

The authors declare that there are no any potential financial, academic, or personal interest inherent to this manuscript.

\section{Ethics}

The study was approved by the Ethics Committee (Ref. CEIFE-038-013). 